\title{
Correction to: Seasonal variation in groundwater quality and beneficial use for drinking, irrigation, and industrial purposes from Deccan Basaltic Region, Western India
}

\author{
Ajaykumar Kadam ${ }^{1} \cdot$ Vasant Wagh $^{2}$ (D) $\cdot$ Sanjay Patil ${ }^{3} \cdot$ Bhavana Umrikar $^{4} \cdot$ Rabindranath Sankhua $^{5} \cdot$ James Jacobs $^{6}$ \\ Published online: 19 February 2021 \\ (C) Springer-Verlag GmbH Germany, part of Springer Nature 2021
}

\section{Correction to: Environmental Science and Pollution Research} https://doi.org/10.1007/s11356-020-12115-x

The correct copyright is presented in this paper.

The original article has been corrected.

The online version of the original article can be found at https://oi.org/ $10.1007 / \mathrm{s} 11356-020-12115-\mathrm{x}$

Vasant Wagh

wagh.vasant@gmail.com

Ajaykumar Kadam

kadamajaykumar1@gmail.com

Sanjay Patil

drsnpati19@gmail.com

Bhavana Umrikar

bnumrikar@gmail.com

Rabindranath Sankhua

sankhua12@yahoo.com

James Jacobs

geojimj@gmail.com
1 Department of Environmental Sciences, Savitribai Phule Pune University, Pune, Maharashtra, India

2 School of Earth Sciences, Swami Ramanand Teerth Marathwada University, Nanded, Maharashtra, India

3 Department of Applied Geology, School of Environmental \& Earth Sciences, KBC North Maharashtra University,

Jalgaon, Maharashtra 425 001, India

4 Department of Geology, Savitribai Phule Pune University, Pune 411007, India

5 Basin Planning, Central Water Commission, New Delhi 110066 , India

6 Clearwater Group 229, Tewksbury Avenue Pt, Richmond, CA 94801, USA 